Case Report

\title{
Cutaneous metastasis: Indicators of internal malignancy diagnosed on fine needle aspiration cytology
}

\author{
Giriyan S.S. ${ }^{1}$, Chandan R.H. ${ }^{2}$, Agrawal A. ${ }^{3}$ \\ ${ }^{1}$ Dr. Sujata S Giriyan, Professor and Head of the department, ${ }^{2}$ Dr. Rajesh H Chandan, Associate Professor, \\ ${ }^{3}$ Dr. Akanksha Agrawal, Resident, all authors are affiliated with Department of Pathology, Karnataka Institute of Medical \\ Sciences, Hubballi, Karnataka, India.
}

Corresponding author: Dr. Akanksha Agrawal, Resident, Department of Pathology, Karnataka Institute of Medical Sciences, Hubballi, Karnataka, India, Email: aki2003@gmail.com

\begin{abstract}
Introduction: Cutaneous metastases (CM) from various malignancies are uncommon with incidence of $0.8-4 \%$ and indicate disseminated disease with poor outcome. Metastatic adenocarcinoma to the skin occurs from gastro-intestinal tract, breast, lung and ovary and can be determined by high index of suspicion. Fine needle aspiration cytology is commonly employed for its diagnosis. CM from breast carcinoma to the chest wall are not very rare; however, distant $\mathrm{CM}$ are far less common occurring mostly within five years of its complete resection. Gastric adenocarcinoma presenting as $\mathrm{CM}$ is extremely rare, with $6 \%$ males and $1 \%$ females presenting likewise. Classically, these lesions appear as slowgrowing, painless, discrete hard nodules with intact overlying epidermis. Case Report: We describe three cases of CM from malignancies of two organs \& diagnosed on FNAC - 1) A 65 year male who underwent complete resection for breast carcinoma 10 years ago, presented with chest wall metastasis, 2) A 42 year female presented with distant CM following complete treatment for breast carcinoma 4 years ago, and 3) A 52 year female presented with CM nodules over abdomen after 3 years of radical gastrectomy and adjuvant chemotherapy. Conclusion: CM can be the first sign of disseminated malignancy; primary or post-surgery. CM can also occur in response to chemotherapy. Post-surgery, such skin lesions could occur as part of dissemination from another organ malignancy (dual malignancy). FNAC is a costeffective, precise procedure for diagnosis of $\mathrm{CM}$ and also helps in differentiating these from various primary cutaneous malignancies and inflammatory conditions.
\end{abstract}

Key words: Cutaneous nodules, Skin metastasis, subcutaneous metastasis

\section{Introduction}

Cutaneous and subcutaneous metastases from internal malignancies arerare[1]. Incidence of such metastasis rises with advancing age, especially after the fifth decade of life [2]. Metastatic adenocarcinoma to the skin occurs from gastro-intestinal tract, breast, lung and ovary and its diagnosis can be determined by high index of suspicion[3]. Skin metastases are believed to be due to systemic spread and they represent terminal stage of malignant disease with limited survival period[4]. Cutaneous metastasis may occur as the initial manifestation of internal malignancy or late in the course of the disease. Furthermore, they can be the first sign of disseminated neoplasm or an important presenting feature of recurrence after successful therapy[5].
Metastasis to skin from breast carcinoma most commonly occur to the chest wall. However it is also seen at other sites like head and neck, scalp, abdomen. Gastric carcinoma is known for its propensity for recurrence in the tumour bed. Gastric adenocarcinoma presenting as $\mathrm{CM}$ is extremely rare, with $6 \%$ males and $1 \%$ females presenting likewise.

Cutaneous metastasis mainly present as solitary or multiple nodules or as plaques, papules and ulcers $[6,7,8,9,10]$. As an alternative to performing biopsies, fine needle aspiration cytology (FNAC) is fast, minimally invasive method that can be used to diagnose these cases.

\footnotetext{
Manuscript received: $6^{\text {th }}$ March 2018

Reviewed: $16^{\text {th }}$ March 2018

Author Corrected: $25^{\text {th }}$ March 2018

Accepted for Publication: $31^{\text {st }}$ March 2018
} 


\section{Case Report}

\section{Case Report}

Case-1: A 65 year old male patient presented with two swellings in the left lateral side of chest wall for the past 4 months. He had undergone Modified radical mastectomy with adjuvant chemotherapy 10 years back for the infiltrating ductal carcinoma of the left breast. Ultrasonography of the abdomen was done one year back which revealed metastatic deposits in the liver. One swelling measured $11 \mathrm{~cm}$ in diameter while the other measured $9 \mathrm{~cm}$ in diameter. Both swellings were firm to hard, mobile and non-tender lying in the subcutaneous plane. There were focal areas of ulceration in the skin. No axillary lymph nodes were palpable. Clinically it was diagnosed as a case of disseminated neoplasm with cutaneous metastasis (figure 1). Fine needle aspiration cytology of the swelling revealed highly cellular smears showing atypical plasmacytoid cells with pleomorphic nuclei and dense eosinophilic cytoplasm. Cells were arranged in groups, sheets and singles. Numerous mitotic figures were seen (figure 2). A diagnosis of Metastatic Adenocarcinoma deposits in the chest wall was made.

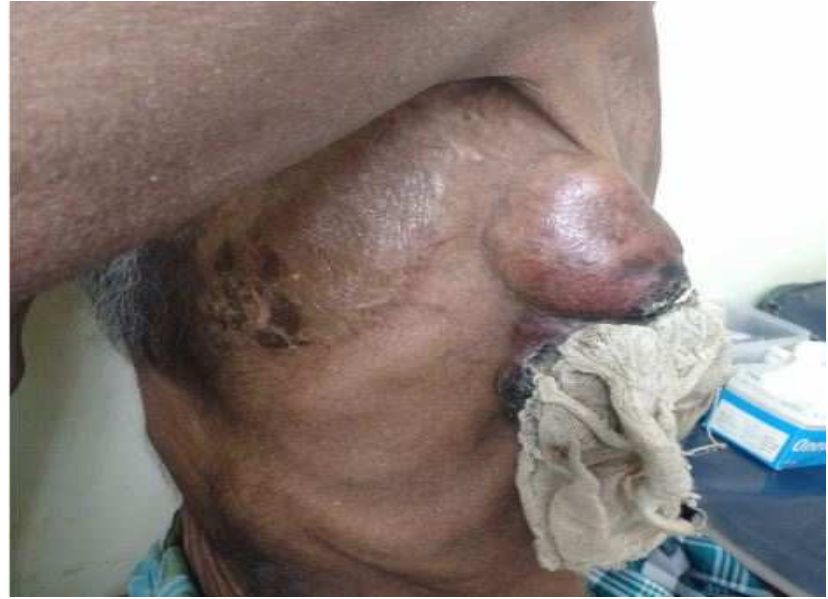

Figure-1: Swelling in the left lateral side of chest wall

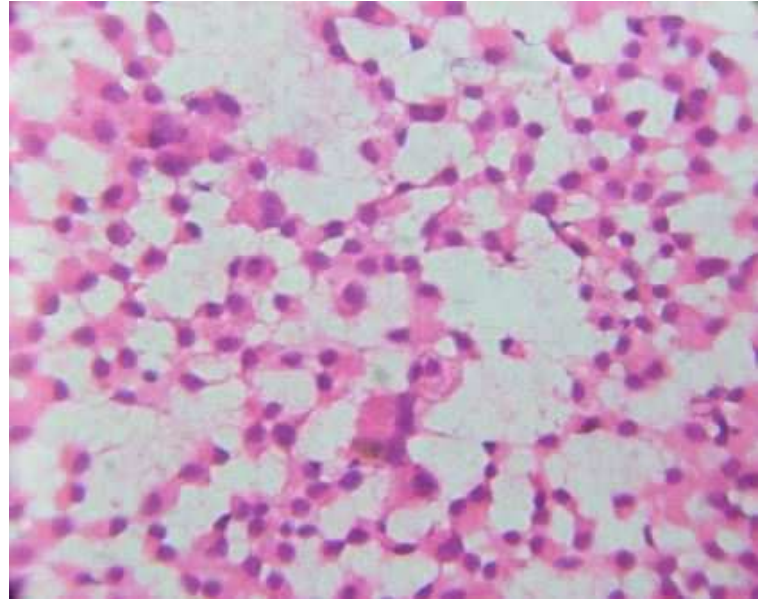

Figure-2: FNAC. High power, 40x; H \& E: Atypical plasmacytoid cells arranged in sheets and acini

Case-2: A 42 year old female presented with a cutaneous swelling in the left supraclavicular region since 2 months. She was a known case of Ductal Carcinoma of the right breast who had undergone complete treatment with neoadjuvant chemotherapy and Modified Radical Mastectomy 4 years back, followed by adjuvant chemotherapy. The swelling measured $2 \mathrm{~cm}$ in diameter. It was firm to hard, slightly mobile with minimal tenderness. No axillary lymph nodes were palpable. A clinical diagnosis of suppurative lesion was made. Fine needle aspiration cytology was performed which showed atypical cells arranged in sheets, clusters and acini, having hyperchromatic nuclei with indistinct nucleoli and moderate amount of cytoplasm. Nuclear overlapping was prominent. It was diagnosed as Metastatic Adenocarcinoma deposits in the skin (figure 3).

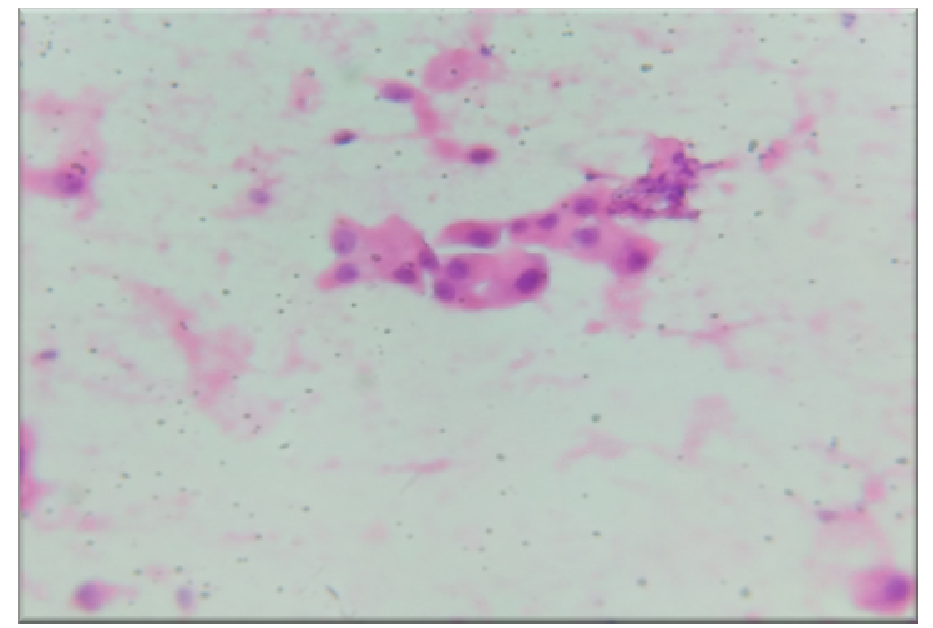

Figure-3: FNAC. High power, 40x; H \& E: Scattered atypical cells forming vague acini 


\section{Case Report}

Case 3: A 52 year old female presented with multiple, discrete nodules over the abdominal wall since 3 months. She was a case of Gastric Adenocarcinoma for which she had undergone radical gastrectomy with adjuvant chemotherapy 3 years back. The nodules were firm to hard in consistency, mobile and non-tender, largest measuring $1.5 \mathrm{~cm}$ in diameter (figure 4). No inguinal lymph nodes were palpable. Fine needle aspiration cytology revealed cellular smears showing atypical cells arranged in singles, groups and vague acini. Cells had hyperchromatic nuclei with prominent nucleoli, moderate amount of cytoplasm and distinct cell borders (figure 5). A diagnosis of Metastatic Adenocarcinoma in the skin was made.

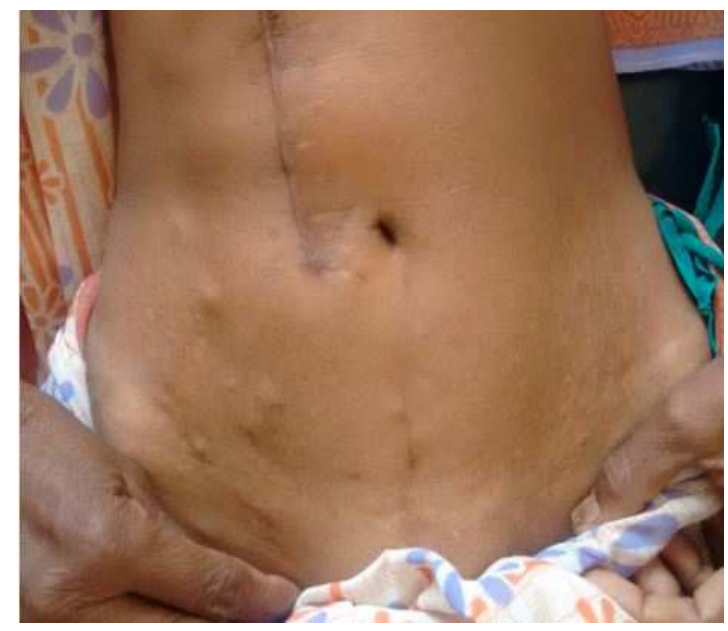

Figure 4: Sub-cutaneous nodules over abdominal wall

\section{Discussion}

Cutaneous Metastasis of internal malignancies is a rare occurrence seen in $0.6-10.4 \%$ of all patients and it represents $2 \%$ of all skin tumors [11]. It can occur secondary to direct extension or either by lymphatic route to regional sites or by haematogenous spread to distant sites [4]. It is important to differentiate metastatic lesions from primary adnexal tumors and primary squamous cell carcinoma of the skin.

Cutaneous metastasis usually occurs close to the site of primary malignancy. Most common sites of metastasis to skin are chest, abdomen, head and neck [5,12]. A study by Bansal et al concluded that Adenocarcinoma of various organs is the commonest to metastasize[4] which is also seen in present case series. The most common malignancy to present as skin metastasis in males is lung carcinoma while in females it is breast carcinoma[12]. Skin metastasis commonly presents as solitary or multiple discrete, firm nodules [11] which may be mobile and minimally tender. This clinical picture is seen in present case series also where in the metastatic breast and gastric carcinoma present as nodules in the skin. Cutaneous metastasis from breast carcinoma is not very rare, reported in about $23.9 \%$ cases[13]. They occur mostly over the chest wall like in the male patient in the current case report. Less common sites include the head and neck. In present

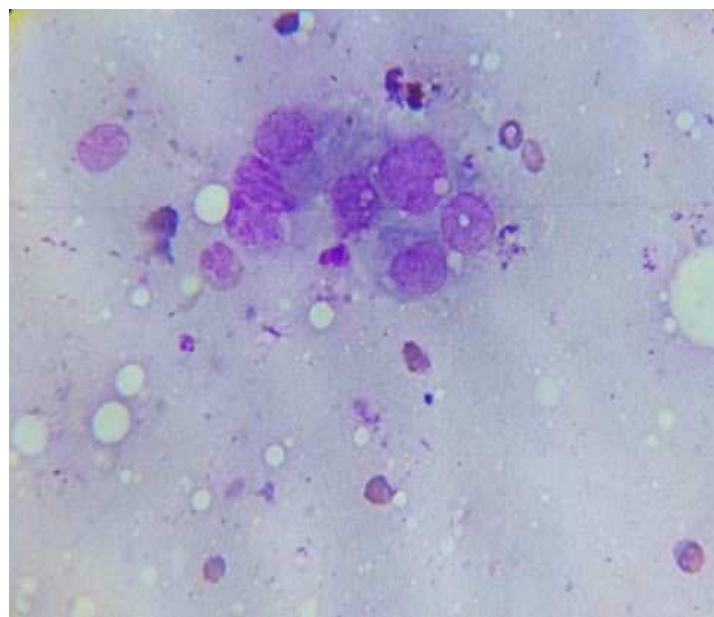

Figure-5: FNAC. High power, 100x; Wright's stain: Atypical cells in singles and vague acini

report the female patient with recurrent breast carcinoma presented with a supra-clavicular nodule. Cutaneous metastasis present as nodular lesions which appear within five years of complete treatment of the primary according to Di Giorgi et al [13]. In the present case series, the male patient presented with recurrence of breast carcinoma after 10 years of complete treatment (figure 1) while the female patient with breast carcinoma presented with a metastatic skin nodule 4 years after treatment.

Cytological picture reveals clusters of atypical epithelial cells arranged in singles, groups or glandular pattern as stated by Shelke et al[14]. A similar picture along with numerous plasmacytoid cells was obtained on FNAC of both metastatic recurrent breast carcinoma cases (figure $2,3)$.

Gastric carcinomas usually metastasize to the liver, peritoneum and regional lymph nodes. Incidence of cutaneous metastasis is less than $1 \%$. Usual presentation of metastatic gastric adenocarcinoma of stomach to skin is in form of nodule at the umbilicus, precisely known as Sister Mary Joseph nodule. A less frequent pattern is in form of multiple, discrete, slow growing nodules over the abdominal wall according to Betke et al[15]. In the present case series, a female patient presented with 


\section{Case Report}

cutaneous metastasis to abdominal wall 3 years after complete treatment of gastric adenocarcinoma (figure 4).

According to Narsimha et al, FNAC smears are cellular showing pleomorphic round to oval cells with vesicular nuclei and eosinophilic cytoplasm arrangedin glandular or papillary pattern with few signet ring cells and mucin background [16]. Third case in this series revealed a similar picture with large round to oval cells arranged in vague acinar pattern (figure 5).

Cutaneous metastasis is considered a poor prognostic sign with minimal survival rate[17]. Cutaneous lesions may be the first sign of disseminated primary malignancy. These may occur as a response to chemotherapy and may also indicate failure of therapy leading to recurrence of a cancer assumed to have been completely treated. Rarely these may occur due to presence or a start of another malignant process (dual malignancy) [18].

Fine needle aspiration cytology is important in easily accessible and palpable lesions. Such metastatic lesions on the skin are clear and accessible. FNAC thus, is a fast, cost-effective and minimally invasive technique for early and accurate diagnosis of cutaneous metastasis. Hence, it helps in implementation of prompt management [19,20,21].

\section{Conclusion}

Clinical diagnosis of CM may not be precise. They may be misleading to give a false sense of disease free state, especially in cases which present many years later after complete treatment. Hence, FNAC is an important and quick tool to diagnose cutaneous metastasis of internal malignancies helping to initiate appropriate management at the earliest.

Funding: Nil, Conflict of interest: None initiated Permission from IRB: Yes

\section{References}

1. Brady LW, O'Neill EA, Farber SH. Unusual sites of metastases. Semin Oncol. 1977 Mar;4(1):59-64.

2. Rolz-Cruz G, Kim CC. Tumorinvasion of the skin. Dermatol Clin. 2008 Jan;26(1):89-102, viii.

3. Asli Turgut Erdemir, Ulviye Atilganoglu, Nahide Onsun, Adnan Somay. Cutaneous Metastasis from Gastric Adenocarcinoma. Indian J Dermatol. 2011 MarApr; 56(2): 236-237.
4. Bansal R, Patel T, Sarin J, Parikh B, Ohri A, Trivedi P. Cutaneous and subcutaneous metastases from internal malignancies: an analysis of casesdiagnosed by fine needle aspiration. Diagn Cytopathol. 2011 Dec;39 (12): 882-7. doi: 10.1002/dc.21485. Epub2010 Nov 2.

5. Brownstein MH, Helwig EB. Patterns of cutaneous metastasis. Arch Dermatol.1972 Jun;105(6):862-8.

6. Cox NH, Coulson LH. Systemic disease and the skin. In: Burns T, Breathnach S, Cox N, Griffiths C, editors. Rook's Textbook Of Dermatology. 8th ed. West Sussex: Wiley Blackwell Publications;2010.p.62.1-113.

7. Karki S, Pathak R, Manandhar U, Koirala S. Metastatic cutaneous and subcutaneous lesions: Analysis of cases diagnosed on fine needle aspiration cytology. JPN 2011;1:37-40

8. Rajagopal R, Arora PN, Ramasastry CV, Kar PK. Skin changes in internal malignancy. Indian J Dermatol VenereolLeprol2004;70:221-225

9. Johnson WC. Metastatic carcinoma of the skin: Incidence and dissemination. In: Elder DE, editor. Lever's Histopathology of the Skin. 10th ed. Philadelphia: Lippincott Williams and Wilkins; 2009.p 1149-1157.

10. Ayyamperumal A, Tharini GK, Ravindran V, Parveen B. Cutaneous manifestations of internal malignancy. Indian J Dermatol 2012;57:260-264.

11. Alcaraz I, Cerroni L, Rutten A, Kutzner H, Requena L. Cutaneous Metastasis from internal malignancies: A clinicopathological and immunohistochemical review. Am J Dermatopathol2012;34:347-93.

12. Srinivasan R, Ray R, Nijhawan R. Metastaticcutaneous and subcutaneousdeposits from internal carcinoma. An analysis of cases diagnosed by fine needle aspiration. ActaCytol.1993Nov-Dec;37(6):894-8.

13. De Giorgi V, Grazzini M, Alfaioli B, Savarese I, Corciova SA, Guerriero G, Lotti T. Cutaneous manifestations of breast carcinoma. Dermatol Ther. 2010 Nov-Dec; 23 (6):581-9. doi: 10.1111/j.1529-8019. 2010.01365.x.

14. Shelke VN, Khandekar SL, Lodha ND, Raut WK. Multiple Remote Cutaneous Metastases from Male Breast Carcinoma: Cytodiagnosis of a Case. J Cytol Histol 2012, 3:148. 


\section{Case Report}

15. Betke M, Suss R, Hohenleuther U, Lubke S, Eckert F. Gastric Carcinoma metastatic to the site of a congenital melanocytic nevus. J Am Acad of Dermatol 1993; 28:866-9.

16. Narsimha A, Kumar H. Gastric Adenocarcinoma deposits presenting as multiple cutaneous nodules: A Case report with review of literature. Turkish Journal of Pathology 2012;28(1):83-86.

17. Reingold IM. Cutaneousmetastases from internal carcinoma. Cancer. 1966 Feb;19(2):162-8.

18. Pak HY, Foster BA, Yokota SB. The significance of cutaneous metastasis from visceraltumors diagnosed by fine-needle aspiration biopsy. Diagn Cytopathol. 1987 Mar; 3(1):24-9.
19. Rana S, Marwah N, Jain P, Gupta S, Marwah S, Sen R. Fine needle aspiration study of the abdominal cutaneous and subcutaneous nodules. Iran J Dermatol 2012; 15:50-55.

20. Gattuso P, Castelli MJ, Reyes CV, Reddy V. Cutaneous and subcutaneous masses of the chest wall. A fine needle aspiration study. Diagn cytopatho 11996; 15:374-6.

21. David O, Kluskens L, Reddy V, Gattuso P. Malignant cutaneous and subcutaneous abdominal wall lesions: a fine-needle aspiration study. Diagn Cytopathol. 1998 Oct;19(4):267-9.

\section{How to cite this article?}

Giriyan S.S, Chandan R.H, Agrawal A. Cutaneous metastasis: Indicators of internal malignancy diagnosed on fine needle aspiration cytology. Trop J Path Micro 2018;4(1):67-71. doi: 10.17511/jopm.2018.i1.12. 